\title{
Comorbidities, Metabolic and Malignancy Risk Profile in Patients with Psoriasis
}

H Husein-ElAhmed, A Molina-Leyva, GA Cañadas-De la Fuente, R Fernandez-Castillo

\section{INTRODUCTION}

Psoriasis is a hereditary skin disorder of unknown etiology which affects to $1-3 \%$ of the general population worldwide. The most common physical symptom of psoriasis is the presence of thick, dry, red skin lesions in form of plaques covered by silvery scales. The extent of body surface areas affected by this condition is variable, ranging from limited disease $(<2 \%$ body surface affected) in nearly $80 \%$ of patients to more extensive skin involvement in $20 \%$ of patients. As a chronic inflammatory cutaneous disease, psoriasis is associated with impairments which affect to the quality of life of patients even in limited or mild cases. Despite of improvements in therapies with biologic agents, there are emerging comorbidities associated with this cutaneous condition as patients with psoriasis show higher incidence of comorbidities than expected (1-6). Such comorbidities include: obesity, diabetes, cardiovascular disease, different types of cancer, depression, inflammatory bowel disease and psoriatic arthritis. Although the relationship between psoriasis and most of comorbidities is not completely clear, it is likely to be linked to the inflammatory nature of psoriasis. However, epidemiological studies suggest the role of the psoriasis as an independent risk factor of these outcomes. Advances in the knowledge of the pathogenesis of psoriasis and these comorbidities have discovered common physiopathologic mechanisms which may provide a biological plausibility of the associations and explain why such disorders are more frequently observed in these patients through epidemiological studies.

Keywords: Comorbidities, psoriasis

From: ${ }^{1}$ Department of Dermatology, Hospital General de Baza, Granada, Spain, and ${ }^{2}$ Department of Dermatology, Hospital Torrecardenas, Almeria, Spain, Faculty of Health Sciences, The University of Granada, Spain.

Correspondence: Dr H Husein-ElAhmed, Department of Dermatology, Avda Dr Oloriz s/n 18012 Granada Spain. Fax: 0034958023326, email: huseinelahmed@ hotmail.com 


\section{PSORIATIC ARTHRITIS}

Psoriatic arthritis (PsA) is defined as a spondyloarthropathy characterized by synovitis, enthesitis, dactylitis and spondylitis. It is a well-established comorbidity associated with psoriasis. This condition was first described by Aliber (7) in 1818 who observed elevated incidence of joint disease in patients with psoriasis. Despite of in serial cases studies this comorbidity is observed in up to $34 \%$ of patients, popular-based studies show that psoriatic arthritis affects to no more than $4-8 \%$ of patients with psoriasis(8). Since in less than $20 \%$ of patients musculoskeletal symptoms are present before the classic cutaneous manifestations of psoriasis (9) (PsA sine psoriasis), it is important to keep this condition in mind for early detection of the disease and institution of treatment: in these patients, where the key skin manifestations are absent, the correct diagnosis will depend solely on the recognition of specific features of the joint disease. HLA-B27 seems to play a role in the pathogenesis: a high rate of HLA-B27 marker has been found in an important subgroup of patients with psoriatic arthritis (10). In addition, HLA-B27 has been linked to those psoriasis with late on-set (type II psoriasis) (11).

This condition is uncommon in children and usually affects to young persons, typically in their third of fourth decade. It is characterized by swelling, tenderness and pain of joints. The severity of psoriatic arthritis is not parallel to severity of skin lesions (12). Symptoms in joint are quite variable ranging from minimal arthritis to severe case with polyarthritis with joint damage and loss of movility (13). Enthesopathy is a major feature of psoriatic arthritis (often underdiagnosed) affecting more frequently plantar fascia or Aquilles tendons. Dactylitis, an inflammation of the joints and tendons of the whole digit affects to $15-45 \%$ of patients. Five different clinical patterns of psoriatic arthritis have been described (14). These patterns include: Distal interphalangeal 
(classic), Arthritis mutilans, Symmetrical polyarthritis, Asymmetrical oligoarthritis and Spondyloarthropathy. These patterns may overlap, particulary in patients with longstanding disease.

As one of subtypes of seronegative arthropathies, majority of patients with PsA (85\%) have rheumatoid factor negative and this feature is necessary not make the diagnosis (Table 1). Laboratory parameters of inflammation (C-reactive protein and erythrocyte sedimentation rate) are frequently normal or minimally elevated in PsA. Some typical features in the X-rays include: Pencil-in-cup appearance of the joints, resorption of ht distal tuft and irregular periosteal bone proliferation. Nevertheless, there are no radiological, clinical or serologic signs pathognomonic for the detection of this condition. Thus the diagnosis is based on clinical features: Enthesopathy, dactylitis, spinal involvement and periosteal proliferation. Two different scores can be used to make the diagnosis (Table 2). Ultrasonography and magnetic resonance are useful for detecting enthesopathy at the very earliest stage of psA. Bone marrow edema beside to the entheseal insertion is characteristic and is thought to be a manifestation of underlying osteitis.

Asymmetrical oligoarthritis and Spondyloarthropathy patterns may be particularly difficult to distinguish from other seronegative spondyloarthropathies: Clinical and radiological features of these two patterns are similar to those of reactive arthritis which may present with wide range of skin rash and lesions complicating the differential diagnosis. PsA and rheumatoid factor-negative rheumatoid arthritis share some characteristics, therefore, in some cases, it is difficult to distinguish one condition from other with unrelated psoriasis. Specific characteristics of PsA which are usually not present in rheumatoid arthritis include asymmetric arthritis, dactylitis, enthesitis, proliferative bone changes and distal interphalangeal joint damage (16). PsA typically 


\section{Comorbidities, Metabolic Malignancy Psoriasis}

has a relative asymmetry of spinal/sacroiliac involvement and more periosteal and/ or syndesmosmophytes reaction compated to ankylosing spondylitis or spondyloarthritides related to inflammatory bowel disease. The classic pattern of PsA (distal interphalangeal involvement) may be misdiagnosed with osteoarthritis, particularly inflammatory erosive osteoarthritis. The key sign to make the correct diagnosis is the concomitant psoriatic nail involvement in the majority of patients with PsA. Pitting is the most common psoriatic nail lesion, while subungueal hyperkeratosis, nail bed discoloration, transverse grooves or longitudinal ridging or onycholysis may be seen as well. In addition, the fine interpretation of X-ray may help to distinguish this condition from osteoarthritis: the lack of apposition of adjacent bony margins is characteristic of PsA, unlike in osteoarthritis the osseous surfaces are typically closely applied. In addition, the presence of irregular excrescences of bone tissue and the lack of juxtaarticular osteoporosis strongly support the diagnosis of PsA.

Some clinical predictive factors for progressive disease include polyarticular involvement, elevated acute phase reactants, erosive joint disease, physical disability and lack of response to inicial therapeutic agents. About $20 \%$ of patients may suffer from this severe destructive progress of the disease. Futhermore, these patients experience a reduced quality of life and increased functional dysfunction compared to the general population (17). Finally, Patients with PsA have higher rate of mortality and cardiovascular complications which has been found as the first cause of death in this group (18).

The enhanced knowledge and understanding of the pathogenesis of PsA has led to the introduction of highly specific drugs in the arsenal of treatments for PsA. Most of experience with some of these drugs has been obtained from rheumatoid arthritis and 
ankylosing spondylitis. The type of therapy for PsA depends on the severity of joint damage at the time of presentation. Moderate cases may be controlled with nonsteroidal anti-inflammatory drugs. This therapeutic group produces symptomatic relief, but do not have any effect on the progression of the joint diasease and some of them can worsen the skin disease. Severe cases with destructive progression or polyarticular involvement need early administration of traditional disease modifying antirheumatic drugs such as methotrexate, leflunomide, cyclosporine and sulphasalazine. Biologic agents, particulary TNF $\alpha$ antagonists, (infliximab, etanercept and adalimumab) have shown significant effect in treating cases refractory to drug therapies, however the precise impact of these therapies on the disease course remains unknown. Futhermore, combinated therapy of two or more non-biologic drugs or one biologic agent and nonbiologic drugs has proved to be superior to monotherapy in PsA. Synovectomy may be considered in patients with refractory arthritis in a single involved joint.

\section{CARDIOVASCULAR COMORBIDITIES}

\section{Metabolic Syndrome}

Metabolic syndrome (MetS) constitutes a group of lipid and non-lipid cardiovascular risk factor with a metabolic origin. It is defined by the presence of, at least, 3 of the following features: Abdominal obesity, increased insulin resistance/elevated glucose level, decreased high-density lipoprotein cholesterol, hypertriglyceridemia and hypertension (Table 3).

The clinical relevance of MetS is that it defined people with increased long-term risk of cardiovascular diseases, atherosclerosis and diabetes. The reason for this is that 
the combination of risk factors for MetS interacts synergistically to accelerate or start the progression of atherosclerosis and diabetes. Its prevalence is increasing in parallel with population ageing and "epidemic" obesity. The etiology of MetS is unknown with an extremely complex pathophysiology which has only partially elucidated. There is a debate regarding if obesity or insulin resistance is the cause of MetS or the consequences of metabolic dysfunction.

Patients with psoriasis have a high rate of cardiovascular complications and MetS compared to controls without psoriasis (19). In addition, different cross-sectial studies using varying analytic approaches have found connection between isolated components of MetS with psoriasis (20-24).

Those psoriatic patients with MetS have longer mean duration of the disease than those without MetS (22). It is possible that psychosocial inactivity, eating habits, depression, emotional stress and inflammatory cytokines associated with psoriasis contribute to the development metabolic syndrome. All these data suggest that patients with psoriasis may be considered as population with a potential cardiovascular risk, so that the need to counsel them to change their behavior habits. Early diagnosis, prevention and management are the key approaches in reducing this risk.

\section{Dyslipidemia}

The association between dyslipidemia and psoriasis is well-established, with multiple controlled trials supporting it $(19,20,24-26)$. Patients with psoriasis show decreased high density lipoprotein and increased levels of total cholesterol, triglycerides, low density lipoprotein and very low density lipoprotein, all well-known risk factors of 
atherosclerosis. Futhermore, it is interesting that this metabolic profile is present in psoriatic patients at the early onset of the disease, which suggests the presence of dyslipemia is prior to the onset of the skin disease (24). However, findings from population-based studies show that the association between psoriasis and dyslipidemia is not consistent: Such connection disminishes and becomes non-significant when controlling conditions such as obesity and diabetes, which are influence factors in the lipid metabolism (27).

\section{Obesity}

Obesity has become the main metabolic disease in the World. In fact, obesity is a common condition affecting not only in affluent societies, but also in developing contries. Overweight and obesity are measured with the body mass index (BMI): a measure of body fat based on height and weight. Among patients with psoriasis, overweight and obesity (defined as $\mathrm{BMI}>25$ and $\mathrm{BMI}>30$ respectively) are very common according to findings from numerous studies (19,22,24,27-29). Phisiopathologically, adipocites influence in lipid profiles by increasing the levels of proinflammatory cytokines, mainly alpha-tumor necrosis factor and interleukin-6, free fatty acids, cholesterol and tryglicerids. Increasing accumulation of visceral fat leads to the overproduction of these cytokines. Abnormal production of these cytokines by visceral fat contributes to a proinflammatory state. This state is likely to contribute to the health problems associated with obesity and helps to understand the link between obesity and dyslipidemia. If obesity is an independent risk factor to develop psoriasis or a manifestation of psoriasis, it remains unclear. Recent cross-sectional studies suggest that obesity is a risk factor of psoriasis (30-32). In the other hand, data from large population works indicate that increased body mass index is found after the diagnosis of 


\section{Comorbidities, Metabolic Malignancy Psoriasis}

psoriasis, suggesting that obesity is not cause, but effect of psoriasis (33). Irrespective of cause and consequence, what is clear those patients with severe psoriasis shown higher body mass index than patients with light or moderate grade of psoriasis $(27,33)$.

\section{Insulin resistance / Diabetes}

Insulin resistance is a key aspect of the MetS. The extra insulin levels derivated from the insulin resistante can lead directly or indirectly to the characteristic metabolic abnormalities found in patients with MetS. Frequently, the insulin resistance progresses to type 2 diabetes. This condition accompanied with cardiovascular disease is responsible for major mortality and morbility in West society. Multiple epidemiologic studies have found an increased rate of insulin resistance and diabetes in patients with psoriasis compared with controls $(19,23,27,34,35)$. The presence of psoriasis is an independent risk factor for diabetes, such dyslipemia and obesity, based on the findings of a cross-sectional study in UK (27). Due to the high rate of abdominal obsesity and dyslipemia among patients with psoriasis, the association between this skin condition and diabetes is unsurprising. Inflammation could be a biologically plausible mechanism underlying this association, in order that insulin resistance has been previously linked to inflammation $(36,37)$ and elevated C-reactive protein levels are predictive of diabetes $(38,39)$. Therapies for psoriasis with oral steroids may provocate diabetes. Nonetheless, this approach is not the standard and is avoided in psoriatic patients owing the potential for disease worsening. Topical steroids are often used in psoriasis, but only if applied on large body surface areas for long periods, can be absorbed systemically and develop diabetes. Although, the adherence to long-term topical steroid use is low among psoriatic patients and it can't explain the observed increase in risk of diabetes. 
According to two large population-based studies, female psoriatic patients have more risk to develop diabetes than male patients $(1,5)$. The duration of the psoriasis seems to have a link with the insulin resistance, because those patients with long-term psoriasis show less insulin sensitivity when challenged with oral glucose than patient with shortterm disease (40).

\section{Hypertension}

Hypertension is a common manifestation of metabolic disturbances. Although hypertension and psoriasis share common risk factors, such as obesity and smoking, the association between these two conditions is unclear and not well-established by the current literature. Some studies suggest an increased prevalence of hypertension in patients with psoriasis compared to controls $(25,41)$. Possible explanations to this link are the systemic inflammation and the psoriasis treatments: Psoriasis is a chronic inflammatory diasease, and inflammation is considered a risk factor for hypertension $(41,42)$. In the other hand, recent studies have failed to support the relationship between psoriasis or its severity and hypertension (24): A large population-based study of 127,706 patients with psoriasis showed not significant association when controlling risk factors such as obesity and smoking (27).

All these data suggest further researches are needed to clarify the possible association between hypertension and psoriasis, and how the therapies for psoriasis can influence in the levels of blood pressure.

\section{Atherosclerosis}

Atherosclerosis and diabetes are the major factors of mortality and morbidity in west culture. Several lines of research state that psoriasis is associated with enhanced 


\section{Comorbidities, Metabolic Malignancy Psoriasis}

atherosclerosis and risk of cardiovascular disease, being chronic inflammation the converged point between psoriasis and atherosclerosis $(43,44)$. In fact, immunological activities and pro-inflammatory cytokines play an important role in both diaseases, with atherosclerosis sharing multiple pathogenic features with psoriasis. For example, CD4 T-cells are the key cells in the immune compromise with same pattern of adhesion molecules in both conditions (45-50). Histologically, there are also some sharing characteristics between psoriasis and atherosclerosis: infiltrating T-cells, monocytes/macrophages, neutrophils, dendritic cells and mast cells $(51,52)$. The cytokine network in atherosclerosis and psoriasis is mainly based in TNF $\alpha$, IL-2 and INF $\gamma(46,48)$. INF $\gamma$ is an important mediator of inflammation in both atherosclerosis and psoriasis and can stimulate the expression of ICAM-I and MHC class II molecules $(53,54)$. INF $\gamma$ modifies the keratinocyte proliferation and causes a defective cornification leading to typical psoriatic lesion. TNF $\alpha$ activates and increases the keratinocyte proliferation and stimulates the production of C-reactive protein (CRP). Elevations of CRP in blood is a risk factor for cardiovascular disease and seems to be predictive of cardiovascular disease in healthy population $(55,56)$. Futhermore, CRP as well as other plasma acute-phase biomarkers such as fibrinogen and plasminogen activator inhibitor-1 have been found significantly elevated in patients with psoriasis compared to healthy controls and seems to correlate with severity of psoriasis (57-62).

Finally, angiogenesis is a well-established feature common to atherosclerosis and psoriasis with vascular endothelial growth factor (VEGF), which is known as a potent pro-angiogenic factor, upregulated in both conditions. These vascular abnormalities might be the link between these diseases (63-65). In psoriasis, human keratinocytes control the production of VEGF in response to cytokines involved in psoriasis pathogenesis (63). In addition, angiogenesis is also stimulated by pro- 
angiogenic cytokines involved in psoriasis and atherosclerosis involvement such as IL8,IL-1 and TNF $\alpha$.

Given all these features it is reasonable to suggest that psoriatic patients may have a higher risk for cardiovascular disease, therefore detection of subclinical atherosclerosis in psoriatic population is important to prevent cardiovascular disease. Intima-media thickness of the carotid artery is a good indicator of subclinical atherosclerosis, and in patients with psoriatic arthritis it has been correlated with cardiovascular disease risk factors such as BMI, elevated serum glucose levels and elevated blood pressure (66).

Taking into consideration the common mechanism underlying the development of psoriasis and atherosclerosis, therapeutic strategies might be targeted such shared mechanisms and have a positive effect on both conditions. Thus, statins can provide an important canditates as drugs that reduce inflammation and hyperlipidemia leading to theorical improvement in both diseases. The findings of a pilot study in patients with severe psoriasis treated with simvastatin showed a decrease in PASI and elevated highdensity lipoprotein in patients during therapy (67). Other drugs with potential multiple benefits are the thiazolidindiones, which have been suggested to improve psoriasis and cardiovascular risk factors (68).

In the other hand, classic systemic therapies for psoriasis such methotrexate and cyclosporine may reduce the inflammation leading to decreased risk of atherosclerosis. However, these approaches are limited by the security profile with multiple adverse effects as hypertension, dyslipemia, renal and hepatic toxicity. Lastest systemic therapies for psoriasis (biological therapies) may offer an advance in the integrated treatment of inflammation underlying psoriasis and atherosclerosis: Infliximab and 


\section{Comorbidities, Metabolic Malignancy Psoriasis}

etarnecept as TNF $\alpha$-blocking agents, and ustekinumab which blocks the proliferation of CD4 T-cells through the inhibition of IL-12 and IL-23.

In conclusion, further studies are necessary to determinate whether treatment of hyperlipidemia and other cardiovascular risk factors associated with psoriasis would result in clinical improvement of the skin disease or alternatively treatment of psoriasis could improve cardiovascular disease.

\section{Myocardial Infarction}

Myocardial infarction caused 1 of every 5 deaths in the US in 2004. Approximately $38 \%$ of individuals who experience a coronary attack in a given year will die as a consequence (69). $18 \%$ of men and $23 \%$ of women who survive a first myocardial infarction at age of 40 , will die within the first year. This figures rise to $33 \%$ (men) and $43 \%$ (women) within 5 years. Those patient who survive the acute stage of myocardial infarction have a 1.5 to15-fold higher risk of death and illness than general population (70). All these data demonstrate that myocardial infarction is a major medical event, therefore it is essential define if patients with psoriasis are in higher risk of coronary artery.

Although several hospital-based studies have suggested the association between myocardial infarction and psoriasis, no control of bias was considered in the study design (71-75). A recent well-designed prospective study based on data from the UK General Practice Research Database states that psoriasis is an independent risk factor for myocardial infarction after controlling possible confounding factors such as hypertension, diabetes, history of myocardial infarction, hyperlipemia, age, sex, smoking and BMI (76). According to the findings of this study, the risk of myocardial 
infarction is greatest in young patients with severe forms of psoriasis and decreases with age, and this risk has a dose-response effect: patients with severe psoriasis have higher risk of myocardial infarction than those with mild psoriasis.

Equally, a retrospective study in psoriasis population in Europe, Canada and US shows that patients with moderate to severe psoriasis have greater 10 -year risk for coronary heart disease than the general population (77). However, based on the severity of psoriasis no significant difference in risk of coronary heart disease was found once the threshold of a PASI $\geq 10$ is met (77). This finding does not exclude the possible difference in risk of myocardial infarction between patients with a PASI $<10$ and those with more severe psoriasis. As mentioned previously, the involvement of CD4 T-cells and pro-inflammatory cytokines is the growing evident link between psoriasis and atherosclerosis and coronary artery disease.

Additional studies should be performed to confirm these results and determinate the implication of clinical markers of psoriasis activity (eg, PASI and duration of the disease) and biomarkers of inflammation, such as C-reactive protein, on the risk of myocardial infarction.

\section{Stroke}

Stroke is a leading cause of mortality, and many who survive experience functional disability, with up to $30 \%$ being permanently disabled and $20 \%$ requiring institutuional care(78).Major risk factors for stroke include diabetes, hypertension and smoking, which also predispone to cardiovascular disease in general. However, there are other minor factors, but more specific, such as atrial fibrillation and transient ischemic attack. Emerging data from cohort and case-control studies $(79,80)$ suggest that psoriasis may be an independent risk factor for stroke. Futhermore, according to these results, there is 


\section{Comorbidities, Metabolic Malignancy Psoriasis}

a dose-response effect: those patients with severe psoriasis have $43 \%$ increased risk of stroke compared to patients with moderate psoriasis (79). Similarly to the rest of cardiovascular diseases, the systemic inflammation is the possible underlying pathology linking these two conditions.

\section{MISCELLANEOUS}

\section{Crohn Disease}

Crohn disease (CD) is an inflammatory disorder of the gastrointestinal tract. As psoriasis, it has a peak age of onset in the second to fourth decades of life. In patients with CD psoriasis is approximately 5 times more frequent (81-83). In addition, there are existing data suggesting that psoriasis and CD may share a common genetic etiology: The interleukin-23 is a proinflammatory cytokine which has an important key role in psoriasis regulating the molecules of innate defense such as IL-17 and IL-22 (84-85). The gene for interleukin-2 receptor has been demonstrated to have a significant association with both $\mathrm{CD}(86)$ and psoriasis (87-90).

\section{Malignancies}

Association between psoriasis and cancer risk has received considerable attention in the last years. The incidence of some cancers in patients with psoriatic, particulary lymphoma, has been reported to be increased $(91,92)$. However, to determinate the contribution of psoriasis to the cause of lymphoma is complicated due to the rare nature of this malignancy and the inconsistent or difficult to interpret findings from studies. The risk of lymphoma and solid malignancies in patients with psoriasis may be 
attributable to the pathophysiology or/and the use of immune-suppresive and potentially carcinogenic treatments such as methotrexate, ciclosporin, psoralen, ultraviolet A (PUVA) therapy and biologic agents. PUVA regimens has been implicated in the development of squamous cell carcinoma $(93,94)$. Futhermore, use of cyclosporine has been associated with non-melanoma skin cancer (95).

In addition to lymphomas, some studies suggest that others malignancies are linked to psoriasis such as those of head and neck, lung, liver, pancreas, breast, kidney, genital, and non-melanoma skin cancer(96-98). However, the results of these studies are inconsistent and hard to interpret, possible because of differences in study design or bias. In addition, lifestyle factors associated with psoriasis (e.g. tobacco, diet and alcohol intake) may have acted as confounders in these studies because they were most often not accounted for in the analyses.

A recent population-based prospective well-designed study from de UK General Practice Research Database report that patients with psoriasis seem to be at an increased risk of pancreatic, colon, bladder, kidney and lymphohematopoietic cancers compared to psoriasis-free patients, with no increased risk for other malignancies. This risk tends to be higher in patients with severe and/or long-term disease, independently of the treatment received (99).

Finally, it is important to highlight the complex relationship among psoriasis, cancer risk and medications. With the exception of lymphoma for which the evidence is strongly suggestive, findings to date for solid cancers are inconsistent (recent valid data suggest an association between colon, bladder, kidney, pancreatic and psoriasis)(99). Therefore, further well-designed prospective cohort studies in patients with moderate 


\section{Comorbidities, Metabolic Malignancy Psoriasis}

and severe psoriasis are warranted to better understanding of cancer risk in patients with psoriasis and the relationship with the duration and severity of the disease.

\section{CONCLUSION}

Since the pathogenesis of psoriasis is understood as a $\mathrm{T}$ lymphocyte mediated autoimmune disease, this condition is considered a systemic condition more than just a cutaneous skin disease. The need for an interdisciplinary assessment of the potential interrelation between some specified comorbidities and psoriasis is warranted. Care should be taken to ensure that patients do receive appropriate screening for the comorbidities associated with psoriasis such as cardiovascular diseases or malignancies.

\section{TAKE HOME MESSAGES}

- Psoriasis is a systemic T lymphocyte mediated autoimmune disease

- Advances in the knowledge of the pathogenesis of psoriasis and some certain comorbidities have found common etiopathogenic mechanisms

- These comorbidities have shown a higher incidence in psoriatic patients than in general population.

- Physicians should take care to perform appropriate screening for these comorbidities in patients with psoriasis, particularly cardiovascular diseases and malignancies. 
Husein-ElAhmed et al

\section{ACKNOWLEDGES}

Author declare no conflict of interest 


\section{REFERENCES}

1. Lindegard B. Diseases associated with psoriasis in a general population of 159,200 middle-aged, urban, native Swedes. Dermatologica 1986;172:298-304.

2. Naldi L, Parazzini F, Brevi A, et al. Family history, smoking habits, alcohol consumption and risk of psoriasis. Br J Dermatol 1992;127:212-7.

3. Christophers E, Henseler T. Contrasting disease patterns in psoriasis and atopic dermatitis. Arch Dermatol Res 1987;297:48-51.

4. Poikolainen K, Reunala T, Karvonen J. Smoking, alcohol and life events are related to psoriasis among women. Br J Dermatol 1994;130:473-7.

5. Henseler T, Christophers E. Disease concomitance in psoriasis. J Am Acad Dermatol $1995 ; 32: 98$.

6. Pearce DJ, Morrison AE, Higgins KB, et al. The comorbid state of psoriasis patients in a university dermatology practice. J Dermatol Treat 2005;16:319-23.

7. J.L. Alibert, Precise theorique et pratique sur les maladies de la peau.Vol. 1 Paris, Caille et Ravier, 1818, p21.

8. Wilson FC, Icen M, Crowson CS, McEvoy MT, Gabriel SE, Kremers HM. Incidence and clinical predictors of psoriatic arthritis in patients with psoriasis: a populationbased study. Arthritis Rheum 2009: 61: 233-239.

9. Gottlieb AB, Mease PJ, Mark Jackson J, et al. Clinical characteristics of psoriatic arthritis and psoriasis in dermatologists' offices. J Dermatolog Treat. 2006;17:279287.

10. Enno Christophers. Comorbidities in psoriasis. Clinics in Dermatology (2007) 25, $529-534$.

11. Rahman P, Schentag CT, Gladman DD. Immunogenetic profile of patients with psoriatic arthritis varies according to age at onset of psoriasis. Arthritis Rheum 
$1999 ; 42: 822-3$.

12. Cohen MR, Reda DJ, Clegg DO. Baseline relationships between psoriasis and psoriatic arthritis: analysis of 221 patients with active psoriatic arthritis. Department of Veterans Affairs Cooperative Study Group on Seronegative Spondyloarthropathies. J Rheumatol. 1999;26:1752-1756.

13. Queiro-Silva R, Torre-Alonso JC, Tinture-Eguren T, et al. A polyarticular onset predicts erosive and deforming disease in psoriatic arthritis. Ann Rheum Dis. 2003;62:68-70.

14. Moll JM, Wright V. Psoriatic arthritis. Semin Arthritis Rheum. 1973; 3:55-78.

15. Taylor W, Gladman D, Helliwell P, et al. Classification criteria for psoriatic arthritis: development of new criteria from a large international study. Arthritis Rheum. 2006;54:2665-2673.

16. Gottlieb A, Korman NJ, Gordon KB, et al. Guidelines of care for the management of psoriasis and psoriatic arthritis: Section 2. Psoriatic arthritis: overview and guidelines of care for treatment with an emphasis on the biologics. J Am Acad Dermatol. 2008;58:851-864.

17. Husted JA, Gladman DD, Farewell VT, et al. Validating the SF-36 health survey questionnaire in patients with psoriatic arthritis. J Rheumatol. 1997;24:511-517.

18. Gladman DD, Antoni C, Mease P, et al. Psoriatic arthritis: epidemiology, clinical features, course, and outcome. Ann Rheum Dis. 2005;64(suppl 2):ii14-17.

19. Sommer DM, Jenisch S, Suchan M, et al. Increased prevalence of themetabolic syndrome in patients with moderate to severe psoriasis. Arch Dermatol Res. 2006;298:321-328.

20. Akhyani M, Ehsani AH, Robati RM, et al. The lipid profile in psoriasis: a controlled 


\section{Comorbidities, Metabolic Malignancy Psoriasis}

study. J Eur Acad Dermatol Venereol. 2007; 21:1330-1332.

21. Boehncke $\mathrm{S}$, Thaci D, Beschmann $\mathrm{H}$, et al. Psoriasis patients show signs of insulin resistance. Br J Dermatol. 2007;157:1249-1251.

22. Cohen AD, Gilutz H, Henkin Y, et al. Psoriasis and the metabolic syndrome. Acta Derm Venereol. 2007;87:506-509.

23. Cohen AD, Dreiher J, Shapiro Y, et al. Psoriasis and diabetes: a population-based cross-sectional study. J Eur Acad Dermatol Venereol.2008;22:585-589.

24. Mallbris L, Granath F, Hamsten A, et al. Psoriasis is associated with lipid abnormalities at the onset of skin disease. J Am Acad Dermatol. 2006;54:614-621.

25. Han C, Robinson DW Jr, Hackett MV, et al. Cardiovascular disease and risk factors in patients with rheumatoid arthritis, psoriatic arthritis, and ankylosing spondylitis. $J$ Rheumatol. 2006;33:2167-2172.

26. Tekin NS, Tekin IO, Barut F, et al. Accumulation of oxidized lowdensity lipoprotein in psoriatic skin and changes of plasma lipid levels in psoriatic patients. Mediators Inflamm. 2007;2007:78454.

27. Neimann AL, Shin DB, Wang X, et al. Prevalence of cardiovascular risk factors in patients with psoriasis. J Amer Acad Dermatol 2006; 55:829-835.

28. Sterry W, Strober BE, Menter A, on behalf of the International Psoriasis Council. Obesity in psoriasis: the metabolic, clinical and therapeutic implications. Report of an interdisciplinary conference and review. Br J Dermatol 2007; 157:649-655.

29. Gisondi P, Tessari G, Conti A, et al. Prevalence of metabolic syndrome in patients with psoriasis: a hospital-based case-control study. Br J Dermatol 2007; 157:68-73.

30. Setty AR, Curhan G, Choi HK. Obesity, waist circumference, weight change, and the risk of psoriasis in women: Nurses' Health Study II. Arch Int Med 2007; 167:1670-1675. 
31. Huerta C, Rivero E, Rodriguez LA. Incidence and risk factors for psoriasis in the general population. Arch Dermatol 2007; 143:1559-1565.

32. Naldi L, Chatenoud L, Linder D, et al. Cigarette smoking, body mass index, and stressful life events as risk factors for psoriasis: results from an Italian case-control study. J Invest Dermatol. 2005;125:61-67.

33. Herron MD, Hinckley M, Hoffman MS, et al. Impact of obesity and smoking on psoriasis presentation and management. Arch Dermatol. 2005;141:1527-1534.

34. Shapiro J, Cohen AD, David M, et al. The association between psoriasis, diabetes mellitus, and atherosclerosis in Israel: a case-control study. J Am Acad Dermatol 2006; 56:629-634.

35. Brauchli YB, Jick SS, Miret M, et al. Psoriasis and risk of incident myocardial infarction, stroke or transient ischaemic attack: an inception cohort study with a nested case-control analysis. Br J Dermatol. 2009;160:1048-1056.

36. Duncan BB, Schmidt MI, Pankow JS; et al, Atherosclerosis Risk in Communities Study. Low-grade systemic inflammation and the development of type 2 diabetes: the Atherosclerosis Risk in Communities Study. Diabetes. 2003;52(7):1799-1805

37. Syrenicz A, Garanty-Bogacka B, Syrenicz M, Gebala A, Walczak M. Low-grade systemic inflammation and the risk of type 2 diabetes in obese children and adolescents. Neuro Endocrinol Lett. 2006;27(4):453-458.

38. Pradhan AD, Manson JE, Rifai N, Buring JE, Ridker PM. C-reactive protein, interleukin 6, and risk of developing type 2 diabetes mellitus. JAMA. 2001;286(3):327 -334.

39. Yuan G, Zhou L, Tang J; et al. Serum CRP levels are equally elevated in newly 


\section{Comorbidities, Metabolic Malignancy Psoriasis}

diagnosed type 2 diabetes and impaired glucose tolerance and related to adiponectin levels and insulin sensitivity. Diabetes Res Clin Pract. 2006;72(3):244-250.

40. Reynoso-von Drateln C, Martinez-Abundis E, Balcazar-Munoz BR,et al. Lipid profile, insulin secretion, and insulin sensitivity in psoriasis. J Am Acad Dermatol. 2003;48:882-885.

41. Cohen AD, Sherf M, Vidavsky L, et al. Association between psoriasis and the metabolic syndrome. Dermatol 2008; 216:152-155.

42. Wakkee M, Thio HB, Prens EP, Sijbrands EJ, Neumann HA. Unfavorable cardiovascular risk profiles in untreated and treated psoriasis patients. Atherosclerosis. 2007;190(1):1-9.

43. Alexandroff A.B, Pauriah M Camp RD. et al. More than skin deep: atherosclerosis as systemic manifestation of psoriasis. Br J Dermatol. 2009;161:1-7

44. Abou-Raya A, Abou-Raya S. Inflammation: a pivotal link between autoimmune diseases and atherosclerosis. Autoimmun Rev. 2006;5:331-7.

45. Biedermann T, Röcken M, Carballido JM. TH1 and TH2 lymphocyte development and regulation of TH cell mediated immune responses of the skin. J Invest Dermatol. 2004;9:5-14

46. Gudjonsson JE, Johnston A, Sigmundsdottir H. et al. Immunopathogenic mechanisms in psoriasis. Clin Experience Immunol. 2004;135:1-8

47. Hansson GK. Immune mechanisms in atherosclerosis. Arterioscler Thromb Vasc Biol. 2001;21:1876-90

48. Hansson GK, Libby P. The immune response in atherosclerosis: a double-edged sword. Nat Rev Immunol. 2006;6:508-19

49. Schön MP, Boehncke WH. Psoriasis. N Engl J Med. 2005;352:1899-12

50. Blankenberg S, Barbaux S, Tiret L. Adhesion molecules and atherosclerosis. 
Atherosclerosis. 2003;170:191-203

51. Nickoloff BJ, Nestle FO. Recent insights into the immunopathogenesis of psoriasis provide new therapeutic opportunities. J Clin Invest. 2004;113:1664-75

52. Nickoloff BJ, Qin JZ, Nestle FO. Immunopathogenesis of psoriasis. Clin Rev Allergy Immunol. 2007;33:45-56

53. Krueger JG. The immunologic basis for the treatment of psoriasis with new biologic agents. J Am Acad Dermatol. 2002;46:1-23

54. Ranjbaran H, Sokol SI, Gallo A. et al. An inflammatory pathway of IFN-gamma production in coronary atherosclerosis. J Immunol. 2007;178:592-604.

55. Koenig W, Khuseyinova N, Baumert J. et al. Increased Concentrations of CReactive Protein and IL-6 but not IL-18 Are independently associated with incident coronary events in middle-aged men and women. Arterioscler Thromb Vasc Biol. $2006 ; 26: 2745-51$

56. Ridker PM, Rifai N, Cook NR, et al. Non-HDL cholesterol, apolipoproteins A-I and B100, standard lipid measures, lipid ratios, and CRP as risk factors for cardiovascular disease in women. JAMA. 2005;294:326-333.

57. Gisondi P, Girolomoni G. Psoriasis and atherothrombotic diseases: Disease-specific and non-disease-specific risk factors. Semin Thromb Hemost. 2009;35:313-24

58. Coimbra S, Oliveria H, Reis F. et al. C-reactive protein and leucocyte activation in psoriasis vulgaris according to severity and therapy. J Eur Acad Dermatol Venereol. 2010;24:789-96.

59. Chodorowska G, Wojnowska D, Juszkiewicz-Borowiec M. C-reactive protein and alpha2-macroglobulin plasma activity in mediumsevere and severe psoriasis. $J$ Eur Acad Dermatol Venereol. 2004;18:180-183.

60. Nielsen HJ, Christensen IJ, Svendsen MN, et al. Elevated plasma levels of vascular 


\section{Comorbidities, Metabolic Malignancy Psoriasis}

endothelial growth factor and plasminogen activator inhibitor-1 decrease during improvement of psoriasis. Inflamm Res. 2002;51:563-567.

61. Vanizor Kural B, Orem A, Cimsit G, et al. Evaluation of the atherogenic tendency of lipids and lipoprotein content and their relationships with oxidant-antioxidant system in patients with psoriasis. Clin Chim Acta. 2003;328:71-82.

62. Vanizor Kural B, Orem A, Cimsit G, et al. Plasma homocysteine and its relationships with atherothrombotic markers in psoriatic patients. Clin Chim Acta. 2003;332:23-30.

63. Canavese M, Altruda F, Ruzicka T. et al. Vascular endothelial growth factor (VEGF) in the pathogenesis of psoriasis--a possible target for novel therapies?. $J$ Dermatol Sci. 2010;58:171-6

64. Inoue M, Itoh H, Ueda M. et al. Vascular endothelial growth factor (VEGF) expression in human coronary atherosclerotic lesions: possible pathophysiological significance of VEGF in progression of atherosclerosis. Circulation. 1998;98:210816.

65. Herrmann J, Lerman LO, Mukhopadhyay D. et al. Angiogenesis in atherogenesis. Arterioscler Thromb Vasc Biol. 2006;26:1948-57.

66. Kimhi O, Caspi D, Bornstein NM, et al. Prevalence and risk factors of atherosclerosis in patients with psoriatic arthritis. Semin Arthritis Rheum. 2007;36:203-209.

67. Shirinsky IV, Shirinsky VS. Efficacy of simvastatin in plaque psoriasis: A pilot study. J Am Acad Dermatol. 2007;57:529-31.

68. Shafiq N, Malhotra S, Pahndhi P. et al. Pilot trial: pioglitazone versus placebo in patients with plaque psoriasis (the P6). Int J Dermatol. 2005;44:328-33.

69. Rosamond W, Flegal K, Furie K, et al; American Heart Association Statistics 
Committee and Stroke Statistics Subcommittee. Heart disease and stroke statistics—2008 update: a report from the American Heart Association Statistics Committee and Stroke Statistics Subcommittee. Circulation. 2008;117:e25-e146.

70. Mokdad AH, Ford ES, Bowman BA, et al. Prevalence of obesity, diabetes, and obesity-related health risk factors, 2001. JAMA. 2003; 289:76-79.

71. McDonald CJ, Calabresi P. Complication of psoriasis. JAMA. 1973;224:629.

72. McDonald CJ, Calabresi P. Occlusive vascular disease in psoriatic patients. $N$ Engl J Med. 1973;288:912.

73. Ena P, Madeddu P, Glorioso N, Cerimele D, Rappelli A. High prevalence of cardiovascular diseases and enhanced activity of the renin-angiotensin system in psoriatic patients. Acta Cardiol. 1985;40:199-205.

74. Henseler T, Christophers E. Disease concomitance in psoriasis. J Am Acad Dermatol. 1995;32:982-986.

75. Mallbris L, Akre O, Granath F, et al. Increased risk for cardiovascular mortality in psoriasis inpatients but not in outpatients. Eur J Epidemiol 2004; 19: 225-230.

76. Gelfand JM, Neimann AL, Shin DB, Wang X, Margolis DJ, Troxel AB. Risk of myocardial infarction in patients with psoriasis. JAMA 2006: 296: 1735-1741.

77. Kimball AB, Guerin A, Dominick Latremouille-Viau et al. Coronary heart disease and stroke risk in patients with psoriasis: retrospective analysis. Am J Med. 2010:123 (4):350-357.

78. Rosamond W, Flegal K, Furie K, Go A, Greenlund K, Haase N et al. (2008) Heart disease and stroke statistics—2008 update. A report from the American Heart Association Statistics Committee and Stroke Statistics Subcommitee. Circulation 117:e25-146.

79. Gelfand JM, Azfar R, Shin D, et al. Incidence of stroke in patients with psoriasis: a 


\section{Comorbidities, Metabolic Malignancy Psoriasis}

population-based study. J Invest Dermatol. 2008;128:81.

80. Kaye JA, Li L, Jick SS. Incidence of risk factors for myocardialinfarction and other vascular diseases in patients with psoriasis. Br J Dermatol. 2008;159:895902.

81. Lee F.I.,Bellary S.V.,Francis C. Increased occurrence of psoriasis in patients with Crohn's disease and their relatives. Am. J. Gastroenterol. 1990;85:962-963.

82. Hoffmann R, Schiefferstein G, Schunter F, et al. Increased occurrence of psoriasis in patients with Crohn's diseases and their relatives. Am J Gastroenterol 1991;86:787-83. 83. Yates VM,Watkinson G, Kelman A. Further evidence for an association between psoriasis, Crohn's disease and ulcerative colitis. Br J Dermatol 1982;106:323-30.

84. Blauvelt A. New concepts in the pathogenesis and treatment of psoriasis: key roles for IL-23, IL-17A and TGF- $\beta$. Expert Rev Dermatol 2007;2:69-78.

85. Mackenzie BS, Kastelein RA, Cua DJ. Understanding the IL-23-IL-17 immune pathway. Trends Immunol 2006;27:17.

86. Duerr GH, Taylor KD, Brant SR, et al. Genome-wide association study identifies IL-23R as an inflammatory bowel disease gene. Science 2006;314:1461.

87. Cargill M., Schrodi S.J., Chang M., Garcia V.E. et al. A large-scale genetic association study confirms IL12B and leads to the identification of IL23R as psoriasis-risk genes. Am. J. Hum. Genet. 2007;80:273-390.

88. Capon F., Di Meglio P., Szaub J., Prescott N.J. et al. Sequence variants in the genes for the interleukin-23 receptor (IL23R) and its ligand (IL12B) confer protection against psoriasis. Hum. Genet. 2007;122:201-206.

89. Smith R.L., Warren R.B., Eyre S., Ho P. et al. Polymorphisms in the IL-12beta and IL-23R Genes Are Associated with Psoriasis of Early Onset in a UK Cohort. J. 
Invest. Dermatol. 2007;128:1325-1327.

90. Nair R.P., Ruether A., Stuart P.E., Jenisch S., et al. Polymorphisms of the IL12B and IL23R genes are associated with psoriasis. J. Invest. Dermatol. 2008;128:1653-1661.

91. Margolis D, Bilker W, Hennessy S, et al. The risk of malignancy associated with psoriasis. Arch Dermatol. 2001;137:778-783.

92. Gelfand JM, Shin DB, Neimann AL, et al. The risk of lymphoma in patients with psoriasis. J Invest Dermatol. 2006;126:2194-2201.

93. Nijsten TE, Stern RS. The increased risk of skin cancer is persistent after discontinuation of psoralen_ultraviolet A: a cohort study. J Invest Dermatol. 2003;121:252-258.

94. Lindelof B, Sigurgeirsson B, Tegner E, et al. PUVA and cancer risk: the Swedish follow-up study. Br J Dermatol. 1999;141:108-112.

95. Behnam SM, Behnam SE, Koo JY. Review of cyclosporine immunosuppressive safety data in dermatology patients after two decades of use. J Drugs Dermatol. 2005;4:189-194.

96. Boffetta P, Gridley G, Lindelof B (2001) Cancer risk in a population-based cohort of patients hospitalized for psoriasis in Sweden. J Invest Dermatol 117:1531-1537.

97. Olsen JH, Moller H, Frentz G. Malignant tumors in patients withpsoriasis. J Am Acad Dermatol. 1992;27:716-722.

98. Frentz G, Olsen JH. Malignant tumours and psoriasis: a follow-up study. $B r J$ Dermatol. 1999;140:237-242.

99. Brauchli YB, Jick SS, Miret M, Meier CR. Psoriasis and risk of incident cancer: an 


\section{Comorbidities, Metabolic Malignancy Psoriasis}

inception cohort study with a nested case-control analysis. J Invest Dermatol. 2009 Nov;129(11):2604-12. 
Table 1: Seronegative arthropathies.

\begin{tabular}{|c|}
\hline SERONEGATIVE ARTHROPATHIES \\
\hline Reiter syndrome (reactive arthritis) \\
\hline Ankylosing spondylitis \\
\hline Juvenile spondiloarthritis \\
\hline Enteropathic arthropathy \\
\hline Psoriatic arthritis \\
\hline Undifferentiated spondiloarthritis \\
\hline Isolated peripheral enthesitis \\
\hline
\end{tabular}


Table 2: Criteria for diagnosis of psoriatic arthritis.

\begin{tabular}{|c|c|}
\hline MOLL AND WRIGHT CRITERIA(14) & $\begin{array}{l}\text { CLASSIFICATION CRITERIA FOR } \\
\text { PSORIATIC ARTHRITIS(15) }\end{array}$ \\
\hline 1. Presence of psoriasis & $\begin{array}{l}\text { 1. Presence of established inflammatory } \\
\text { articular disease }\end{array}$ \\
\hline $\begin{array}{l}\text { 2. Inflammatory arthritis accompanied by } \\
\text { one of the following: }\end{array}$ & $\begin{array}{l}\text { 2. At least } 3 \text { points of the following features: } \\
\text { - Current psoriasis ( } 2 \text { points) }\end{array}$ \\
\hline $\begin{array}{l}\text { - Polyarticular symmetric arthritis } \\
\text { - Oligoarticular (<5 joints) asymmetric arthritis }\end{array}$ & $\begin{array}{l}\text { - Personal history of psoriatic arthritis (1 } \\
\text { point) }\end{array}$ \\
\hline - Distal interphalangeal joint involvement & - Family history of psoriasis (1 point) \\
\hline - Predominant spondylitis & - Past or present dactylitis (1 point) \\
\hline - Arthritis mutilans. & $\begin{array}{l}\text { - Yuxtaarticular new bone formation (1 point) } \\
\text { - Rheumatoid factor negativity ( } 1 \text { point) } \\
\text { - Psoriatic nail distrophy (1 point) }\end{array}$ \\
\hline
\end{tabular}


Table 3: Diagnostic criteria for metabolic syndrome. HDL: High Density Lipoprotein.

\begin{tabular}{|c|c|}
\hline \multicolumn{2}{|c|}{ DIAGNOSTIC CRITERIA FOR METABOLIC SYNDROME } \\
\hline Elevated waist circumference & $\geq 88 \mathrm{~cm}$ in women; $\geq 102 \mathrm{~cm}$ in men \\
\hline Elevated triglycerides & $\geq 150 \mathrm{mgr} / \mathrm{dL}$ \\
\hline Reduced HDL cholesterol & $<40 \mathrm{mgr} / \mathrm{dL}$ in men \\
\hline Elevated blood pressure & \\
\hline Elevated glucose & \\
\hline & \\
\hline & \\
\hline & \\
& \\
\hline
\end{tabular}

